\title{
Moderating Effects of Individual Differences in Causality Orientation on Relationships between Reward, Choice, Perceived Competence, and Intrinsic Motivation
}

\author{
Juming Jiang', Misaki Kusamoto², \& Ayumi Tanaka² \\ ${ }^{1}$ Graduate School of Psychology of Doshisha University, Japan ${ }^{a}$ \\ ${ }^{2}$ Faculty of Psychology of Doshisha University, Japan ${ }^{\mathrm{b}}$
}

Article received 20 November 2020 / Article revised 24 June 2021/ Accepted 25 June / Available online 12 August

\begin{abstract}
This study examined whether individual differences in causality orientation moderate the effects of monetary reward and choice on perceived competence, which affect intrinsic motivation in turn. Causality orientation refers to an individual's tendency to experience or interpret events in a social context in a specific way and to behave accordingly, and is directly related to the development of intrinsic motivation. We randomly assigned 103 undergraduate students to one of four conditions: reward (reward vs. no reward) $\times$ choice (choice vs. no choice). Participants were presented with puzzles to solve in the experimenters' presence, and they were free to continue working on it once the experimenters left the room. We measured the time spent on solving puzzles when participants were free to choose other activities, and used self-reported feedback on task enjoyment as an index for intrinsic motivation. We also measured perceived competence as a mediator. Task enjoyment was unaffected by reward in participants with high autonomy orientation, but dropped significantly in participants with low autonomy orientation. Choice over task increased perceived competence in participants with high autonomy orientation, but lowered perceived competence in the case of low autonomy orientation. We found no significant effects for time spent on puzzles. The present study contributes to current understandings of the causes of performance differences in various settings.
\end{abstract}

Keywords: monetary reward; choice; intrinsic motivation; causality orientation. 


\section{Introduction}

Enhancing and sustaining individuals' motivation have been a long-standing issue in applied settings such as education and the workplace. Intrinsic motivation, where an activity is undertaken for its inherent satisfaction, rather than some separable consequence, is considered the most important and desirable type of motivation (Deci \& Ryan, 2000). Not only does intrinsic motivation strongly relate to individuals' engagement and performance, but it is also significant for improving physical and mental health (Huang et al., 2016; Li et al., 2015; Putra et al., 2017).

Intrinsic motivation can be significantly influenced by external environmental factors, such as the provision of monetary reward and choice (Cerasoli et al., 2014; Patall et al., 2008). The effect of the external environment on intrinsic motivation differs according to individual differences, including culture (e.g., Iyengar \& Lepper, 2000; WANG \& Guthrie, 2004), age (e.g., Catania \& Randall, 2013; Lepper et al., 2005), gender (e.g., Omansky et al., 2016, Skaalvik \& Skaalvik, 2004), self-concept (e.g., Bong \& Clark, 1999; Khalaila, 2015), and need for achievement (Covington \& Müeller, 2001) or achievement goals (e.g., Elliot \& Hulleman, 2017; Rawsthorne \& Elliot, 1999). Thus, the joint function of environmental factors and internal psychological processes should be considered to facilitate intrinsic motivation. Researchers have paid far less attention to an important individual factor directly related to the development of intrinsic motivation: causality orientation. Causality orientation is an individual tendency to perceive and organize motivationally relevant information in a specific way (Deci \& Ryan, 1985, 2000). The present research aimed to elucidate how the effect of monetary reward and choice on intrinsic motivation is moderated by individual causality orientation.

\subsection{Basic psychological needs and causality orientations.}

Self-determination theory (SDT; Deci \& Ryan, 2000; Ryan \& Deci, 2017) states that the needs for autonomy, competence, and relatedness are universal, innate, and essential for intrinsic motivation and well-being. Need for autonomy is the psychological need to be the origin of one's own behaviour. Need for competence is the psychological need to interact effectively with one's environment and have opportunities to express one's abilities. Need for relatedness is the psychological need associated with experiencing a sense of belonging and connectedness to others within a social context. When people are more successful at satisfying these three basic psychological needs, they exhibit more intrinsic motivation and internalization of motivation, and integrate cultural values and regulations, resulting in greater behavioural effectiveness and psychological well-being. However, when needs frustration occurs, there is diminished autonomous motivation, along with fragmentation, defensiveness, and rigidity, which results in ill-being (Ryan et al., 2016).

Even though needs satisfaction and frustration have proximal effects across individuals, persistently experiencing differences in contextual supports and deprivation of basic psychological needs can lead to significant individual differences in how people orient to their environments over time, especially with regard to motivation. (Ryan \& Deci, 2017). According to SDT, people can learn to focus more on certain affordances, rewards, or pressures, and develop characteristic approaches to regulating their emotions and behaviours. This concept of individual difference in SDT is described as causality orientation (Deci \& Ryan, 1985, 2000). Causality orientations reflect people's propensities to orient to different motivationally relevant aspects of situations, especially with respect to whether the individuals will exercise autonomy, attend to controls, or fear non-contingent reactions to their initiations and behaviours (McAdams \& Pals, 2006).

Deci and Ryan (1985, 2000; see also Ryan \& Deci, 2017) sort causality orientations into three broad classes: autonomous, controlled, and impersonal. When autonomy orientation dominates, individuals seek opportunities for self-determination and choice; they tend to interpret their existing situations as more autonomy-promoting and organise their actions based on personal goals and interests, rather than controls and constraints. When the controlled orientation dominates, people experience their social context in terms of rewards and social pressures relating to values or interests. People high on 
controlled orientation tend to use external and introjected styles of regulation, and have a low level of intrinsic motivation. When the impersonal orientation dominates, people tend to see their environment as uncontrollable. The impersonal orientation develops as people experience a considerable degree of unpredictable thwarting of their basic psychological needs, leaving them feeling non-autonomous, ineffective, and anxious. People high on impersonal orientation often foster amotivation or a sense of lack of self-control, which leaves them unable to master or take command of themselves or situations.

\subsection{Effect of monetary reward on intrinsic motivation}

One powerful external environmental factor thought to have tremendous impact on intrinsic motivation is monetary reward. The ongoing debate over how external monetary rewards influence intrinsic motivation has continued since the 1970s. On the one hand, some researchers claim that rewards can be used to increase intrinsic motivation and performance (e.g., Byron \& Khazanchi, 2012; Hendijani et al., 2016; Jovanovic \& Matejevic, 2014). Specifically, expected tangible rewards have been found to increase the time of free-choice behaviour and performance on tasks in which individuals have low initial interest; on high-interest tasks, self-reported task enjoyment is positively influenced when rewards signify perceived competence (Cameron, 2001; Cameron, Banko, \& Pierce, 2001).

On the other hand, some researchers believe that the positive influence of extrinsic rewards, especially monetary rewards, on intrinsic motivation is not only temporary but also inherently harmful (e.g. Deci, 1971; Ma et al., 2014; Murayama et al., 2010; Warneken \& Tomasello, 2008). They argue that external rewards are likely to generate an external perceived locus of causality for the task, leading individuals to perceive their actions as being controlled by external contingency rather than personal agency, thus lowering intrinsic motivation. Recent neural evidence has also demonstrated the undermining effect of monetary reward on intrinsic motivation (Ma et al., 2014; Murayama et al., 2010).

\subsection{The moderating effect of individual differences between reward and intrinsic motivation}

People with high autonomy orientation tend to perceive their actions as self-determined, and define their success according to the satisfaction of the three basic psychological needs (Deci \& Ryan, 1985, 2000). Thus, causality orientation could be understood as an intrapersonal bias that moderates the positive or negative effects of environmental factors on intrinsic motivation. For example, it is possible that people who are autonomy-oriented tend to interpret rewards as having an informational function, that is, as signifying their competence at the task, leading to higher intrinsic motivation towards the task; people who are controlled-oriented usually interpret rewards as controlling. Accordingly, Hagger and Chatzisarantis (2011) found the undermining effect of monetary reward on intrinsic motivation to be observed only in controlled-oriented participants, and no such negative effect was observed for participants dominated by autonomy orientation. However, whether perceived competence mediates the interaction effect of autonomy orientation and reward on intrinsic motivation remains unclear.

Based on previous results and theoretical assumptions, we hypothesized that for people with high autonomy orientation, the provision of monetary reward will increase their perceived competence and lead to higher intrinsic motivation. As for people with high controlled orientation, reward will decrease their intrinsic motivation. Further, we assumed that reward would have no significant influence on perceived competence and intrinsic motivation of people with high levels of impersonal orientation. This is because people with high impersonal orientation often foster amotivation, which makes them insensitive to the effects of external environmental factors.

\subsection{Effect of choice on intrinsic motivation}

In the field of motivation, another external environmental factor thought to significantly influence intrinsic motivation is choice. Choice has been suggested to increase people's perception of 
self-determination with greater opportunity to learn about and exercise their ability to manipulate, compare, and analyse information (DeCharms 1968; Deci \& Ryan 1985; Jellison \& Harvey, 1973). Thus, providing choice may support a person's experience of autonomy and sense of competence, in turn leading to higher intrinsic motivation and better performance outcomes (e.g., How et al., 2013. Patall et al., 2010; Ryan \& Deci, 2000).

Despite a great deal of theory and research suggesting that choice is a powerful motivator of behaviour, several studies find that choice may have a negative effect on adaptive motivation and performance outcomes when there are too many options (Iyengar \& Lepper, 2000; Patall, 2012), or when the options exceed the individual's abilities (Ryan \& Deci, 2000; Skinner \& Belmont, 1993). Baumeister et al. (1998) proposed that all acts of choice or self-control are effortful and draw on a limited resource that can be depleted, analogous to a source of energy or strength. Making choices as one form of self-regulation thus can result in a state of fatigue called 'ego-depletion', where the individual experiences a decreased capacity for initiating activity, making choices, or further selfregulate.

\subsection{The moderating effect of individual differences between choice and intrinsic motivation}

Although there is no direct evidence showing that individual differences in causality orientation could moderate the effect of choice on perceived competence and intrinsic motivation, some preliminary studies provide sufficient grounds for an assumption. Previous research showed that in individualistic cultures, personal agency, independence, and autonomy may be central to one's self-concept, whereas in more collectivistic cultures, agency may have much less importance (Markus \& Kitayama, 1991). Similarly, Iyengar and Lepper (1999) found that intrinsic motivation was enhanced most for Caucasian Americans when they were making a personal choice, but for Asian Americans, intrinsic motivation was enhanced most when trusted authority figures or peers made choices for them. However, we would like to argue that it is not cultural differences that moderate the effect of choice, but rather individual differences in causality orientation, shaped by the overall external environment. It is possible that individuals with high autonomy orientation view choice as a chance to demonstrate their competence, leading to higher intrinsic motivation, whereas people with high controlled orientation are more likely to experience ego depletion when facing choice, leading to a decrease of intrinsic motivation towards activities. In line with this assumption, Mouratidis et al (2011) found that students with high relative autonomous motivation were significantly more interested in a class when its overall climate prioritized choice provision, compared to those with low relative autonomous motivation.

Based on the theoretical assumptions and results of previous research, we hypothesized that the provision of choice will improve the intrinsic motivation of people with high autonomy orientation by satisfying their need for autonomy and improving their competence. Choice will have no positive effect on the intrinsic motivation and perceived competence of people with a high controlled orientation as such people can be motivated when their autonomy is supported; however, their motivation might be strongly undermined when their autonomy is thwarted. For the people with high impersonal orientation, we assumed that the enhancing effect of choice on intrinsic motivation will not occur, and that choice will have no positive effect on their competence. This is because people with high impersonal orientation often foster amotivation and are hardly affected by external environmental factors.

\subsection{Interaction effect of reward and choice on Intrinsic motivation}

In real-world contexts, the simultaneous provision of multiple motivators is rather common. However, the interaction between reward and choice has rarely been examined; we only found two studies focusing on this issue. Cohend (1974) found that the effect of choice was essentially zero when a reward external to the choice manipulation was provided, compared to when participants chose the reward they would receive, or when no reward was involved. On the other hand, Marinak (2004) suggested that if individuals have some control over the reward, it is not perceived as controlling, and 
the positive effect of choice on motivation remains. However, no research has yet examined how reward and choice affect competence, and whether the interaction effect of reward and choice would be moderated by individual differences.

Based on the results and theoretical assumptions of previous research, we hypothesized that for people with high autonomy orientation, the simultaneous provision of reward and choice will increase their perceived competence, leading to even higher intrinsic motivation. As for people with high controlled orientation, reward and choice will not increase their competence, but strongly decrease their intrinsic motivation. We also assumed that reward and choice would have no significant influence on perceived competence and intrinsic motivation of people with high impersonal orientation.

\subsection{Present study}

This study examined the moderating effect of causality orientations on the effect of monetary rewards and choice on perceived competence, and whether it affects intrinsic motivation. We further aimed to explore how reward and choice affect competence and intrinsic motivation when provided simultaneously, and whether it will be moderated by causality orientation. Our three hypotheses are presented in Figure 1.
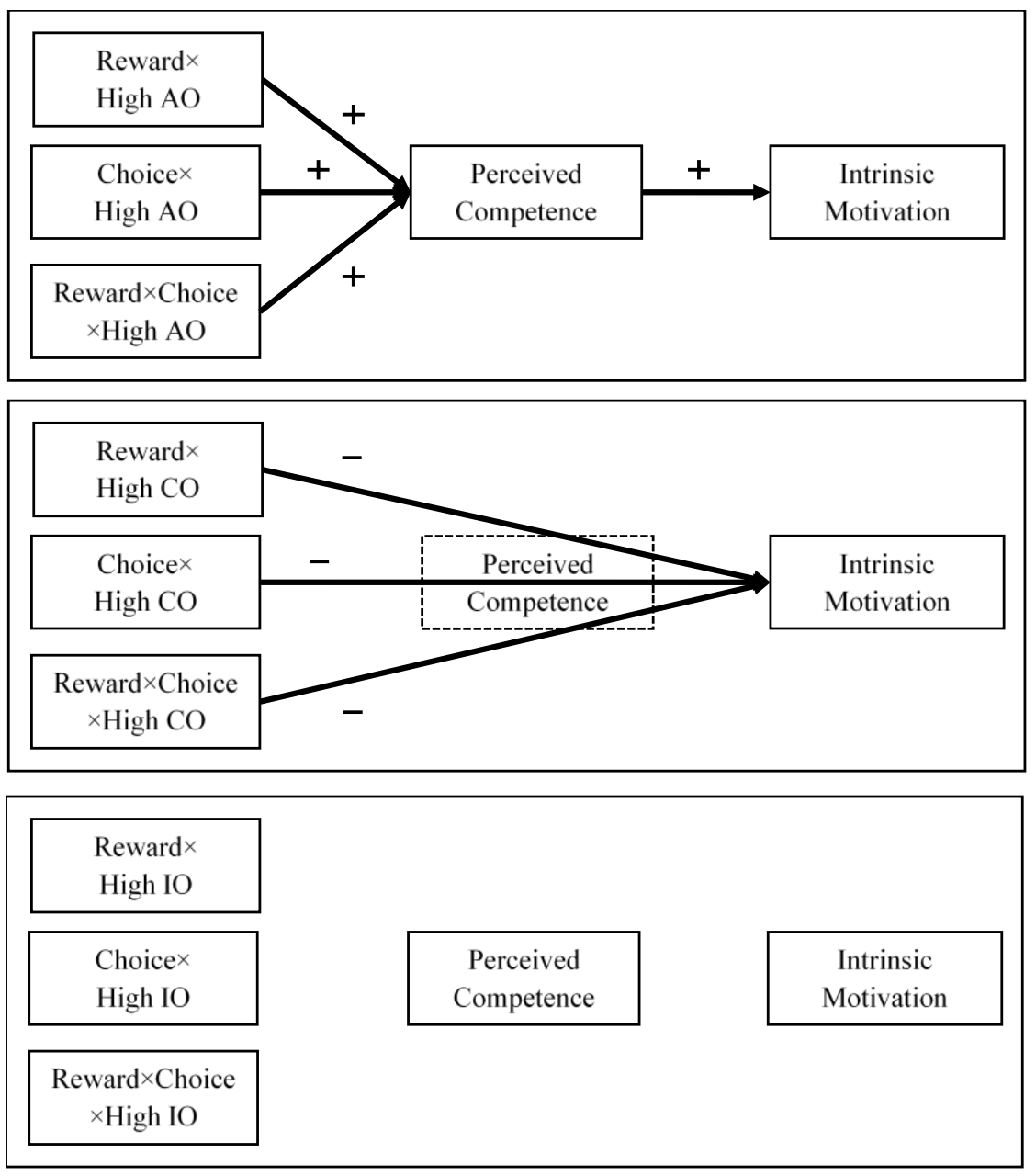

Figure 1. Hypotheses of the moderating effect of causality orientation on the relationships between reward, choice, perceived competence, and intrinsic motivation. 
Note. $\mathrm{AO}=$ Autonomy Orientation, $\mathrm{CO}=$ Controlled Orientation, $\mathrm{IO}=$ Impersonal Orientation.

H1: for people with high autonomy orientation, we hypothesised that reward and choice will increase their perceived competence, which will in turn improve their intrinsic motivation. The positive effects on their competence and intrinsic motivation will be stronger when providing reward and choice simultaneously.

H2: for people with high controlled orientation, the provision of reward and choice will not affect their perceived competence and decrease their intrinsic motivation. These negative effects on their intrinsic motivation will be stronger when providing reward and choice simultaneously.

H3: for people with high impersonal orientation, reward and choice were hypothesised to have no effect on their perceived competence and intrinsic motivation, whether provided separately or together.

\section{Method}

\subsection{Participants}

Participants comprised 103 undergraduate students (41 male, 62 female, $M_{\text {age }}=19.562, S D=$ 1.101) taking an optional psychology class at a private university in Japan. Additional course credits were given to the students who participated in the study. Data were collected from October to November 2017. Informed consent was obtained from all participants and the experiment was authorized by the ethics review committee of the university (16061, 'The effect of individual differences on intrinsic motivation').

\subsection{Task}

We used the solid puzzle (soma cube) used by Deci (1971) as the task of the present study. The puzzle contains seven pieces, all of which are in different shapes. In the present study, the puzzle configurations we asked the participants to replicate were constructed with four pieces; participants needed to figure out which four out of the seven pieces were to be used to solve each puzzle. Before the main experiment, we conducted a pretest to examine whether the task was interesting for university students. A total of 21 university students ( 7 male and 14 female, $M_{\text {age }}=20.841, S D=1.281$ ) enrolled in the pretest. Participants were asked to replicate three out of nine puzzle configurations, which we used in the main experiment. After they had finished solving all the puzzles, their intrinsic motivation towards the task was measured with three items from the Intrinsic Motivation Inventory (see Measures). Participants' mean score on this scale was 6.016 and the standard deviation $(S D)$ was 0.711 . A Wilcoxon rank sum test showed that the mean score was significantly higher than the median of the scale at $p$ $<.001$, indicating that the participants perceived the task as interesting.

\subsection{Experimental Design}

This study adopted the free-choice paradigm of Deci (1971) to examine the effects of rewards and choice on intrinsic motivation. Participants of the main experiment were randomly assigned to one of four conditions: reward (reward vs. no reward) $\times$ choice (choice vs. no choice). Reward in the present research was 100 JPY (about 0.9 US dollars) for each time the participants solved a puzzle, and choice in the present research was provided through the freedom of solving puzzles in the order preferred by the participants. 


\subsection{Procedure}

Time 0

The day on which participants were recruited
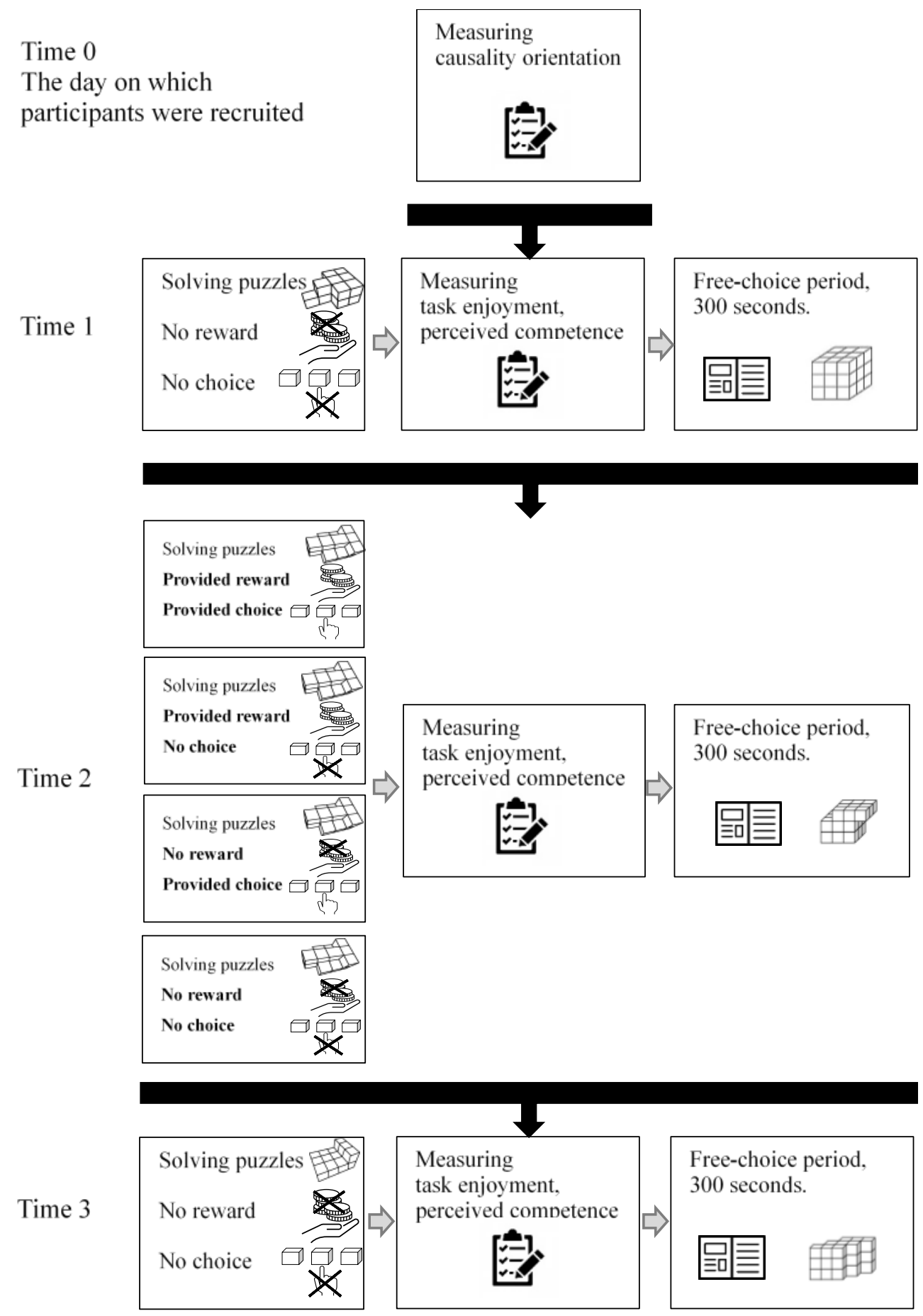

Figure 2. The experimental process flow in the present research.

As shown in Figure 2, participants' causality orientations were measured before the experiment on the day on which they were recruited; the experiment contained three periods in total. At Time 1, all participants 
were presented with three printed illustrations of puzzle configurations and asked to replicate all the puzzles as quickly as possible. No information about a reward was mentioned during this period, and all participants were asked by the experimenters to solve puzzles in a specific order.

At Time 2, all participants were presented with three new printed illustrations of puzzle configurations. Participants assigned to the reward conditions were informed that they would receive 100 JPY after solving each puzzle. Participants in the choice groups were free to solve the puzzles in their preferred order, whereas participants assigned to the no choice conditions were asked by the experimenters to solve the puzzles in a specific order.

At Time 3, all participants were given three new printed illustrations of puzzle configurations again, but none of the participants received monetary reward. Participants in the reward conditions were told that they would not be paid for solving puzzles in this third period because there was only enough money to pay them in one period. All the participants were asked by the experimenters to solve the puzzles in a specific order.

After the participants had solved the puzzles at each period, they were asked to complete a brief measure on their perceptions of the task, including task enjoyment and perceived competence. The experimenters then excused themselves from the laboratory for 300 seconds. In the first and second period, the experimenters told the participants that they needed to fetch more configurations for the next period; in the third period, the experimenters told the participants that they had to fetch another questionnaire covering their task persistence and interest in other puzzles. Just before leaving the room, the experimenters provided the participants a few magazines and an exercise book that contained more illustrations of puzzle configurations. The experimenters then casually informed the participants that they could read those magazines, continue with the puzzles, or engage in any other activity except for leaving the room, till the experimenters returned. Participants' activities in the experimenters' absence were monitored by the experimenters using a hidden video camera. In the end, participants were debriefed about the true purpose of the experiment and the use of hidden camera.

\subsection{Measures}

\subsubsection{Causality orientation}

Autonomy, controlled, and impersonal orientations were measured with the Japanese version (Tanaka \& Sakurai, 1995) of the General Causality Orientations Scale (GCOS; Deci \& Ryan, 1985). The GCOS comprises 12 written vignettes for which participants rate each of the three possible responses, relating to autonomy orientation, control orientation, and impersonal orientation, respectively. For example, one of the vignettes asks: 'You have just received the results of a test you took and discovered that you did very poorly. Your initial reaction is likely to be...' The autonomy-oriented response is, 'I wonder how I did so poorly' (feeling disappointed) (Cronbach's $\alpha=.704$ ); the controloriented response is, 'That stupid test does not show anything' (feeling angry) ( $\alpha=.704)$; and the impersonal-oriented response is, 'I cannot do anything right' (feeling sad) $(\alpha=.633)$. Notice that the original GCOS scores range from 1 to 7, but the scores in the Japanese version ranged from 1 to 4; in order to measure participants' causality orientations as accurately as measured by the original scale, participants in this study provided responses ranging from 1 (very unlikely) to 5 (very likely).

\subsubsection{Intrinsic motivation}

Participants' intrinsic motivation was measured using the time spent on free-choice behaviour and self-reported task enjoyment, both of which are generally used to operationalize intrinsic motivation (e.g., Hendijani et al., 2016, Ng, 2018, Woolley, \& Fishbach, 2018, for meta-analysis, see Cerasoli et al., 2014).

During each of three free-choice periods when the experimenters left the room, the time spent by the participants on the puzzles was considered as the behavioural index for intrinsic motivation towards the task. Each free-choice period lasted 300 seconds. Notice that the configurations presented 
to the participants during the free-choice period were different from the ones presented to them during the tasks, as the former were constructed with all seven pieces of the soma cube puzzle instead of four.

Three items from the Intrinsic Motivation Inventory (Ryan, 1982) were used as a self-report measure of task enjoyment (e.g. 'I enjoyed doing this task'). This measure has been used in several studies in Japan (e.g., Kakinuma et al., 2020; Mogami et al., 2011). Responses were codified via a 7point Likert scale ranging from 1 (not at all) to 7 (very much). The scale's Cronbach's $\alpha$ values were $.894, .883$, and .879 at Times 1,2 , and 3 , respectively.

\subsubsection{Perceived competence}

Participants' perceived competence in the task was measured using three items from the selfdeveloped scale used in Houlfort et al.'s (2002) study, with responses rated on a 7-point Likert scale ranging from 1 (not at all) to 7 (very much) (e.g. 'I am good at this task'). This scale's Cronbach's $\alpha$ values were .937, .902, and .917 at Times 1, 2, and 3, respectively. We carried out an English-toJapanese translation and back-translation procedure for this scale.

\section{Results}

\subsection{Descriptive Statistics}

Three participants were excluded from the final analysis because they did not solve at least one puzzle during the experiment ${ }^{1}$. Table 1 presents the means and SDs of all measures across different study conditions. The mean for autonomy orientation was higher than that for controlled orientation and impersonal orientation, and $83 \%$ of the participants had a higher autonomy orientation than controlled or impersonal orientation. Two-way ANOVA results revealed no significant main effect or interaction effect of reward and choice on the participants' intrinsic motivation measures, perceived competence at Time 1, and causality orientation, indicating that participants were randomly assigned to each of the four conditions. Table 2 presents the correlations between all the variables.

${ }^{1}$ We did not find any sample characteristics that differed for excluded participants after conducting t-tests for all measured variables. 
Table 1

Means (standard deviations) of all measures

\begin{tabular}{|c|c|c|c|c|}
\hline \multirow[b]{2}{*}{ Variables } & \multicolumn{2}{|c|}{ Choice } & \multicolumn{2}{|c|}{ No Choice } \\
\hline & $\begin{array}{l}\text { Reward } \\
(N=24)\end{array}$ & $\begin{array}{c}\text { No Reward } \\
(N=26)\end{array}$ & $\begin{array}{l}\text { Reward } \\
(N=24)\end{array}$ & $\begin{array}{c}\text { No Reward } \\
(N=26)\end{array}$ \\
\hline \multicolumn{5}{|l|}{ Causality Orientation } \\
\hline Autonomy Orientation $^{\mathrm{a}}$ & $\begin{array}{l}3.740 \\
(.480)\end{array}$ & $\begin{array}{l}3.670 \\
(.594)\end{array}$ & $\begin{array}{l}3.758 \\
(.501)\end{array}$ & $\begin{array}{l}3.873 \\
(.355)\end{array}$ \\
\hline Controlled Orientation $^{\mathrm{a}}$ & $\begin{array}{l}3.049 \\
(.539)\end{array}$ & $\begin{array}{l}2.985 \\
(.557)\end{array}$ & $\begin{array}{l}3.008 \\
(.460)\end{array}$ & $\begin{array}{l}3.004 \\
(.352)\end{array}$ \\
\hline Impersonal Orientation $^{\mathrm{a}}$ & $\begin{array}{l}2.911 \\
(.382)\end{array}$ & $\begin{array}{l}3.239 \\
(.509)\end{array}$ & $\begin{array}{l}3.179 \\
(.616)\end{array}$ & $\begin{array}{l}3.068 \\
(.395)\end{array}$ \\
\hline Perceived Competence $^{c}[\mathrm{~T} 1]$ & $\begin{array}{c}3.667 \\
(1.504)\end{array}$ & $\begin{array}{c}4.093 \\
(1.847)\end{array}$ & $\begin{array}{c}3.597 \\
(1.500)\end{array}$ & $\begin{array}{c}3.654 \\
(1.413)\end{array}$ \\
\hline Perceived Competence ${ }^{\mathrm{c}}[\mathrm{T} 2]$ & $\begin{array}{c}4.250 \\
(1.275)\end{array}$ & $\begin{array}{c}4.707 \\
(1.532)\end{array}$ & $\begin{array}{c}4.236 \\
(1.261)\end{array}$ & $\begin{array}{c}3.949 \\
(1.278)\end{array}$ \\
\hline Perceived Competence $^{\mathrm{c}}[\mathrm{T} 3]$ & $\begin{array}{c}4.611 \\
(1.399)\end{array}$ & $\begin{array}{c}4.653 \\
(1.568)\end{array}$ & $\begin{array}{l}4.264 \\
(.997)\end{array}$ & $\begin{array}{c}4.179 \\
(1.437)\end{array}$ \\
\hline \multicolumn{5}{|l|}{ Intrinsic Motivation } \\
\hline Time Spent on Puzzles ${ }^{\mathrm{b}}[\mathrm{T} 1]$ & $\begin{array}{c}193.916 \\
(131.480)\end{array}$ & $\begin{array}{c}231.308 \\
(107.187)\end{array}$ & $\begin{array}{c}209.542 \\
(127.750)\end{array}$ & $\begin{array}{l}243.769 \\
(90.309)\end{array}$ \\
\hline Time Spent on Puzzles ${ }^{\mathrm{b}}[\mathrm{T} 2]$ & $\begin{array}{c}151.208 \\
(141.370)\end{array}$ & $\begin{array}{c}174.885 \\
(137.450)\end{array}$ & $\begin{array}{c}224.708 \\
(132.533)\end{array}$ & $\begin{array}{c}220.269 \\
(124.369)\end{array}$ \\
\hline Time Spent on Puzzles ${ }^{\mathrm{b}}[\mathrm{T} 3]$ & $\begin{array}{c}145.083 \\
(144.690)\end{array}$ & $\begin{array}{c}207.000 \\
(116.758)\end{array}$ & $\begin{array}{c}210.625 \\
(133.292)\end{array}$ & $\begin{array}{c}186.346 \\
(138.094)\end{array}$ \\
\hline Task Enjoyment $^{\mathrm{c}}[\mathrm{T} 1]$ & $\begin{array}{c}5.236 \\
(1.202)\end{array}$ & $\begin{array}{c}5.693 \\
(1.273)\end{array}$ & $\begin{array}{l}5.819 \\
(.927)\end{array}$ & $\begin{array}{l}5.846 \\
(.870)\end{array}$ \\
\hline Task Enjoyment $^{\mathrm{c}}[\mathrm{T} 2]$ & $\begin{array}{c}5.361 \\
(1.016)\end{array}$ & $\begin{array}{c}5.707 \\
(1.207)\end{array}$ & $\begin{array}{l}5.833 \\
(.983)\end{array}$ & $\begin{array}{l}5.769 \\
(.831)\end{array}$ \\
\hline Task Enjoyment $^{\mathrm{c}}[\mathrm{T} 3]$ & $\begin{array}{c}5.319 \\
(1.144)\end{array}$ & $\begin{array}{c}5.947 \\
(1.061)\end{array}$ & $\begin{array}{l}5.847 \\
(.901)\end{array}$ & $\begin{array}{l}5.808 \\
(.839)\end{array}$ \\
\hline
\end{tabular}

Note. ${ }^{\text {a Possible range }}=1-5$ points; ${ }^{b}$ Possible range $=0-300 \mathrm{~s} ;{ }^{\circ}$ Possible range $=1-7$ points. 
Table 2

Correlations between all variables $(N=100)$

\begin{tabular}{|c|c|c|c|c|c|c|c|c|c|c|c|}
\hline Variables & 1 & 2 & 3 & 4 & 5 & 6 & 7 & 8 & 9 & 10 & 11 \\
\hline \multicolumn{12}{|l|}{ Causality Orientation } \\
\hline \multicolumn{12}{|l|}{ 1. Autonomy Orientation } \\
\hline 2. Controlled Orientation & $.427 * *$ & & & & & & & & & & \\
\hline 3. Impersonal Orientation & -.146 & -.054 & & & & & & & & & \\
\hline 4. Perceived Competence [T1] & $.328^{* *}$ & $.418^{* * *}$ & $-.249 *$ & & & & & & & & \\
\hline 5. Perceived Competence [T2] & $.232 *$ & $.398^{* * *}$ & $-.235^{*}$ & $.732 * * *$ & & & & & & & \\
\hline 6. Perceived Competence [T3] & .213 & $.336^{* *}$ & $-.288 * *$ & $.660^{* * *}$ & $.844 * * *$ & & & & & & \\
\hline \multicolumn{12}{|l|}{ Intrinsic Motivation } \\
\hline 7. Time Spent on Puzzles [T1] & .131 & -.001 & .149 & -.010 & .034 & .130 & & & & & \\
\hline 8. Time Spent on Puzzles [T2] & .039 & -.035 & .183 & -.049 & -.053 & -.008 & $.763 * * *$ & & & & \\
\hline 9. Time Spent on Puzzles [T3] & .062 & -.063 & $.242 *$ & .066 & .119 & .066 & $.574 * * *$ & $.656^{* * *}$ & & & \\
\hline 10. Task Enjoyment [T1] & .187 & .203 & -.175 & $.360^{* * *}$ & $.313^{* *}$ & $.348^{* * *}$ & $.235^{*}$ & .184 & $.255^{*}$ & & \\
\hline 11. Task Enjoyment [T2] & $.247^{*}$ & .147 & -.111 & $.322 * * *$ & $.352 * *$ & $.315^{* *}$ & $.245^{*}$ & $.290^{* *}$ & $.390 * * *$ & $.823 * * *$ & \\
\hline 12. Task Enjoyment [T3] & .191 & .080 & -.070 & $.285^{* *}$ & $.312 * *$ & $.289 * *$ & $.316^{* *}$ & $.341^{* *}$ & $.474 * * *$ & $.789 * * *$ & $.852 * * *$ \\
\hline
\end{tabular}

Note. Reward $=1$; no reward $=0$. Choice $=1$; no choice $=0 .{ }^{*} p<.05,{ }^{* *} p<.01,{ }^{* * *} p<.001$ 


\subsection{Moderating effects of causality orientation}

Following the landmark study of Deci (1971), we focused on the difference between Time 1 and Time 3 to examine the interaction effects between causality orientation and the contextual factors of reward and choice on participants' intrinsic motivation ${ }^{2}$. In the present study, we conducted a series of multiple regressions ${ }^{3}$ using causality orientation, reward, and task choice as predictor variables; perceived competence, time spent on puzzles, and task enjoyment at Time 3 as outcome variables; and controlling the objective variables of Time 1 . We also examined the interaction effect between causality orientation and reward, and causality orientation and task choice on outcome variables. Reward vs. no reward and choice vs. no choice conditions were dummy coded as 1 and 0 , respectively. All interaction product terms were constructed using dummy codes and other predictor variables, which were centred (Aiken et al., 1991). For each model, all possible interaction product terms were included in initial analyses, but insignificant interactions were trimmed from the final models. All results reported below are from the final, trimmed models; participants' gender, age, and the number of solved puzzles at Time 3 were controlled in each model.

Table 3 shows the results of multiple regression concerning perceived competence at Time 3 . No significant main effect was found, but the interaction effect between autonomy orientation and choice on perceived competence was significant $(\beta=.341, p=.010)$. Table 4 shows the multiple regression results for time spent on puzzles at Time 3 . The main effects of causality orientation, reward, and choice, and the interaction effects between causality orientation and reward, and causality orientation and task choice were not significant (all $p s>.05$ ). Table 5 shows the results of multiple regression concerning task enjoyment at Time 3. No significant main effect was found in these results, but the interaction effect between autonomy orientation and reward on task enjoyment was significant $(\beta=.211, p=.028)$. Next, we carried out simple slope analyses to further explore these significant interaction effects.

${ }^{2}$ Results of Time 2 are reported in the Appendix section.

${ }^{3}$ In the present study we did not use SEM due to our small sample size. According to Kline (2011), a typical sample size in studies where SEM is used is about 10 cases per parameter. Each model we built has at least 45 parameters, thus requiring about 450 cases. With this in mind, we conducted multiple regression analyses instead. 
Table 3

Multiple regression results concerning perceived competence at Time 3

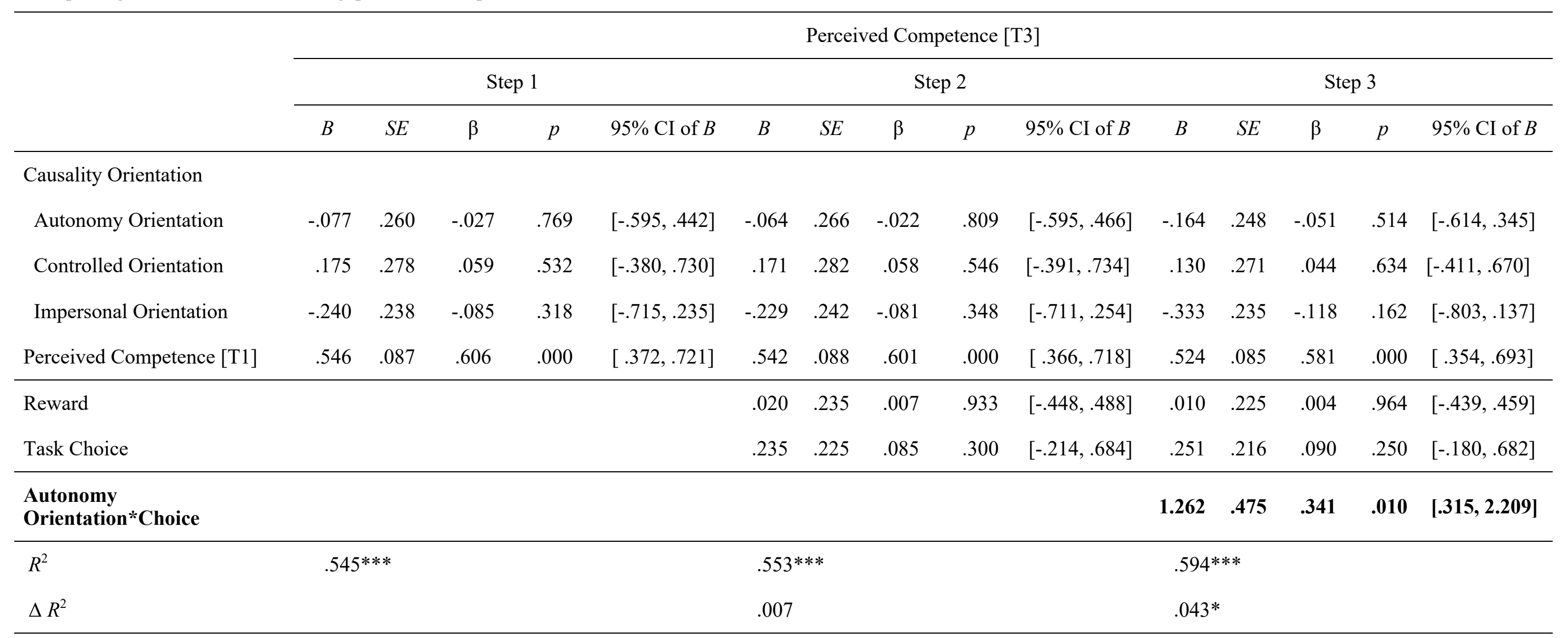

Note. Insignificant interaction effects were removed from the final models. Gender, age, and number of solved puzzles at Time 3 were included as control variables, but results are omitted for brevity. $\Delta R^{2}$ shows the change in $R^{2}$ when adding interaction effects into the model. Given $\Delta R^{2}$ in step 3 at .043, the effect size of $f^{2}$ was calculated to be .092 (Cohen, 2013). 
Table 4

Multiple regression results for time spent on puzzles at Time 3

\begin{tabular}{|c|c|c|c|c|c|c|c|c|c|c|}
\hline & \multicolumn{10}{|c|}{ Time Spent on Puzzles [T3] } \\
\hline & \multicolumn{5}{|c|}{ Step 1} & \multicolumn{5}{|c|}{ Step 2} \\
\hline & $B$ & $S E$ & $\beta$ & $p$ & $95 \% \mathrm{CI}$ of $B$ & $B$ & $S E$ & $\beta$ & $p$ & $95 \%$ CI of $B$ \\
\hline \multicolumn{11}{|l|}{ Causality Orientation } \\
\hline Autonomy Orientation & 12.857 & 30.260 & .046 & .672 & {$[-47.465,73.180]$} & 13.140 & 30.582 & .047 & .660 & {$[-47.853,74.133]$} \\
\hline Controlled Orientation & -24.070 & 30.940 & -.085 & .439 & {$[-85.747,37.607]$} & -23.843 & 30.996 & -.084 & .433 & {$[-85.664,37.977]$} \\
\hline Impersonal Orientation & 42.328 & 27.927 & .155 & .134 & {$[-13.343,97.999]$} & 41.466 & 27.972 & .152 & .143 & {$[-14.321,97.254]$} \\
\hline Time Spent on Puzzles [T1] & .645 & .124 & .536 & .000 & {$[.398, .892]$} & .636 & .126 & .126 & .000 & {$[.385, .887]$} \\
\hline Reward & & & & & & 4.163 & 27.292 & .016 & .879 & {$[-50.270,58.595]$} \\
\hline Task Choice & & & & & & -37.861 & 25.931 & -.141 & .149 & {$[-89.578,13.856]$} \\
\hline$R^{2}$ & .342 & & & & & .362 & & & & \\
\hline$\Delta R^{2}$ & & & & & & .020 & & & & \\
\hline
\end{tabular}

Note. Insignificant interaction effects were removed from the final models. Gender, age, and number of solved puzzles at Time 3 were included as control variables, but the results are omitted for brevity. $\Delta R^{2}$ shows the change in $R^{2}$ when adding interaction effects into the model. 
Table 5

Multiple regression results for task enjoyment at Time 3

\begin{tabular}{|c|c|c|c|c|c|c|c|c|c|c|c|c|c|c|c|}
\hline & \multicolumn{15}{|c|}{ Task Enjoyment [T3] } \\
\hline & \multicolumn{5}{|c|}{ Step 1} & \multicolumn{5}{|c|}{ Step 2} & \multicolumn{5}{|c|}{ Step 3} \\
\hline & $B$ & $S E$ & $\beta$ & $p$ & $95 \%$ CI of $B$ & $B$ & $S E$ & $\beta$ & $p$ & $95 \% \mathrm{CI}$ of $B$ & $B$ & $S E$ & $\beta$ & $p$ & $95 \% \mathrm{CI}$ of $B$ \\
\hline \multicolumn{16}{|l|}{ Causality Orientation } \\
\hline Autonomy Orientation & .231 & .161 & .110 & .154 & {$[-.089, .551]$} & .197 & .164 & .094 & .232 & {$[-.129, .524]$} & -.084 & .202 & -.040 & .680 & {$[-.488, .320]$} \\
\hline Controlled Orientation & -.291 & .166 & -.138 & .078 & {$[-.629, .034]$} & -.275 & .168 & -.128 & .106 & {$[-.610, .060]$} & -.335 & .165 & -.156 & .053 & {$[-.665,-.005]$} \\
\hline Impersonal Orientation & .177 & .147 & .086 & .231 & {$[-.115, .469]$} & .154 & .149 & .074 & .306 & {$[-.143, .450]$} & .193 & .146 & .094 & .190 & {$[-.098, .484]$} \\
\hline Task Enjoyment [T1] & .819 & .075 & .813 & .000 & {$[.669, .969]$} & .805 & .078 & .799 & .000 & {$[.650, .960]$} & .829 & .076 & .823 & .000 & {$[.677, .981]$} \\
\hline Reward & & & & & & -.175 & .147 & -.086 & .238 & {$[-.468, .118]$} & -.163 & .143 & -.080 & .259 & {$[-.448, .123]$} \\
\hline Task Choice & & & & & & -.016 & .142 & -.008 & .910 & {$[-.300, .267]$} & -.009 & .138 & -.005 & .946 & {$[.285, .266]$} \\
\hline Autonomy Orientation*Reward & & & & & & & & & & & .655 & .291 & .211 & .028 & {$[.074,1.235]$} \\
\hline$R^{2}$ & .668 & & & & & .674 & & & & & .697 & & & & \\
\hline$\Delta R^{2}$ & & & & & & .007 & & & & & .022 & & & & \\
\hline
\end{tabular}

Note. Insignificant interaction effects were removed from the final models. Gender, age, and number of solved puzzles at Time 3 were included as control variables, but the results are omitted for brevity. $\Delta R^{2}$ shows the change in $R^{2}$ when adding interaction effects into the model. Given $\Delta R^{2}$ in step 3 at .022 , the effect size of $f^{2}$ was calculated to be .076 (Cohen, 2013 ). 
Figure 3 shows the interaction effect of autonomy orientation and task choice on perceived competence. The results of simple slope analysis revealed that the regression of perceived competence on task choice for people with high autonomy orientation was significant $(B=.852, p=.010)$, indicating that freedom to choose the order in which the participants solve the puzzles increased the perceived competence of participants with high autonomy orientation. The regression of perceived competence on task choice for those with low autonomy orientation was not significant $(B=-.035, p=.263)$.

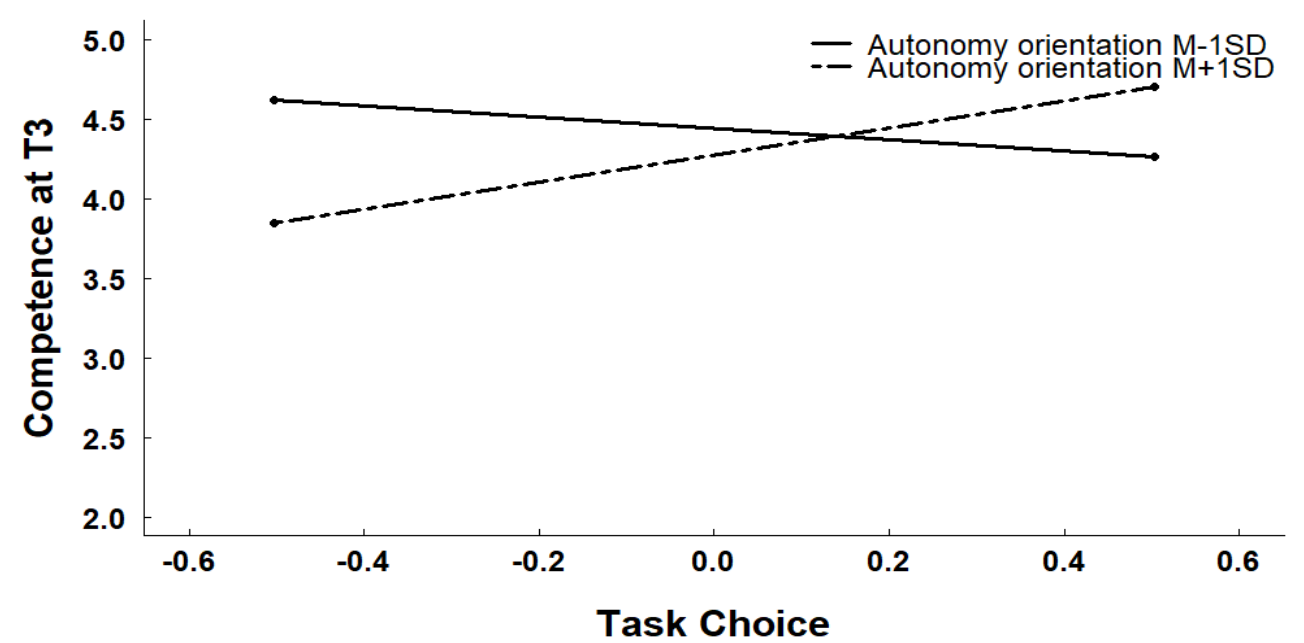

Figure 3. Interaction effect between task choice and autonomy orientation on perceived competence at Time 3.

Note. The no choice and choice conditions were coded as 0 and 1 , respectively.

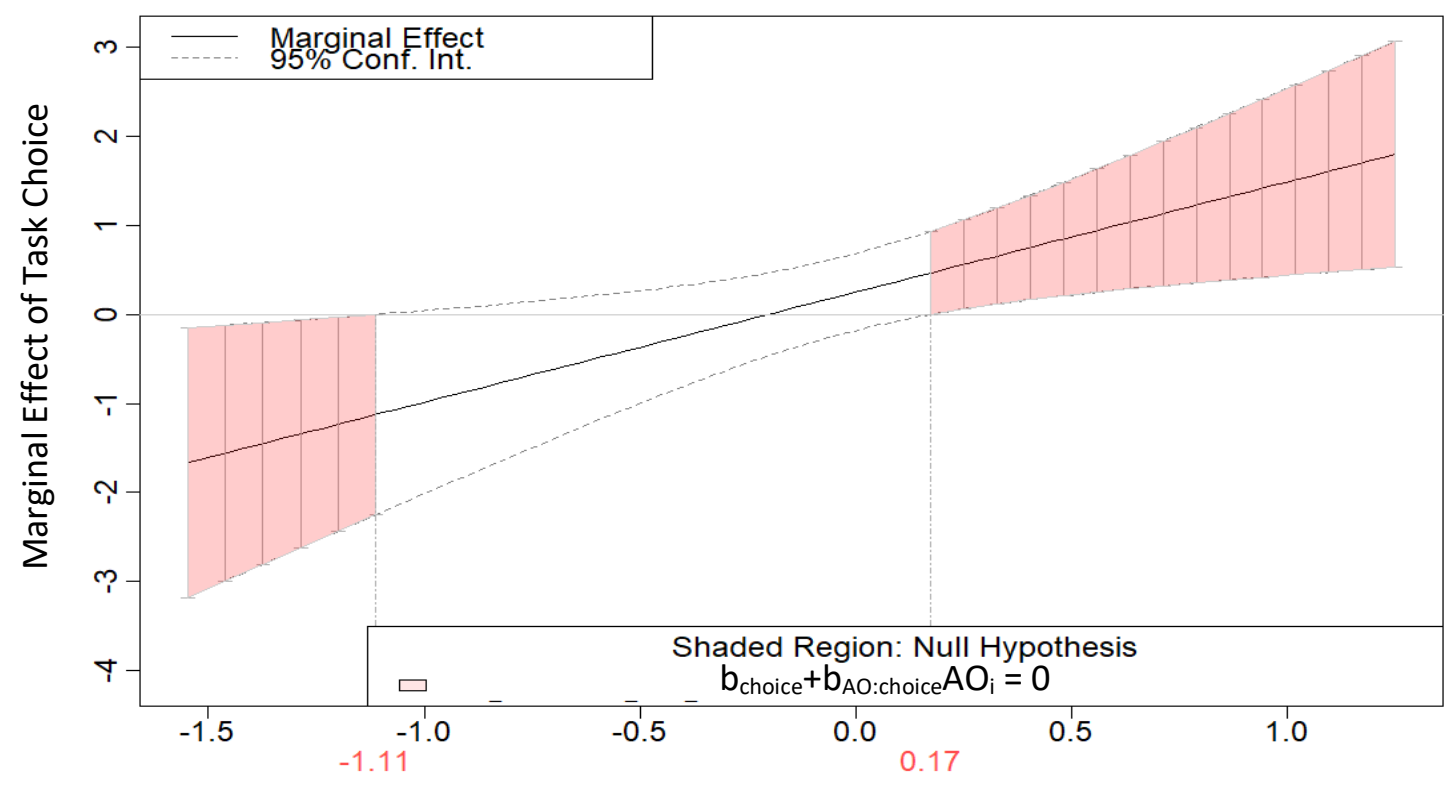

Moderator: Autonomy orientation

Figure 4. Confidence band of the interaction effects of task choice and autonomy orientation (AO) on perceived competence at Time 3.

Note. The standard deviation of centred autonomy orientation was 0.49 and the possible range of centred autonomy orientation was from -1.31 to 1.02 . 
We also calculated the confidence band of interaction effects following the method of Johnson (2019). As depicted in Figure 4, the regression of perceived competence on task choice for people with high autonomy orientation was significant when the centred score of autonomy orientation was higher than .17. Simple slope analysis showed that the regression of perceived competence on task choice for those with low autonomy orientation was not significant when the score of autonomy orientation was 1 SD (.49) less than its mean value; however, the confidence band of interaction effects indicated that the regression of perceived competence on task choice for those with low autonomy orientation was significant when the score of autonomy orientation was lower than -1.11, which is about 2.26 SDs less than the mean. Importantly, -1.11 was within the possible range of centred autonomy orientation (from2.76 to 1.24 ), which means that this result was also substantially significant.

Figure 5 shows the interaction effect of autonomy orientation and reward on task enjoyment. Simple slope analysis revealed the regression of task enjoyment on reward for individuals with low autonomy orientation to be significant $(B=-.489, p=.015)$, indicating that presenting a monetary reward led to lower task enjoyment in participants with low autonomy orientation than when no reward was presented. The regression of task enjoyment on reward for those with high autonomy orientation was not significant $(B=.145, p=.478)$.

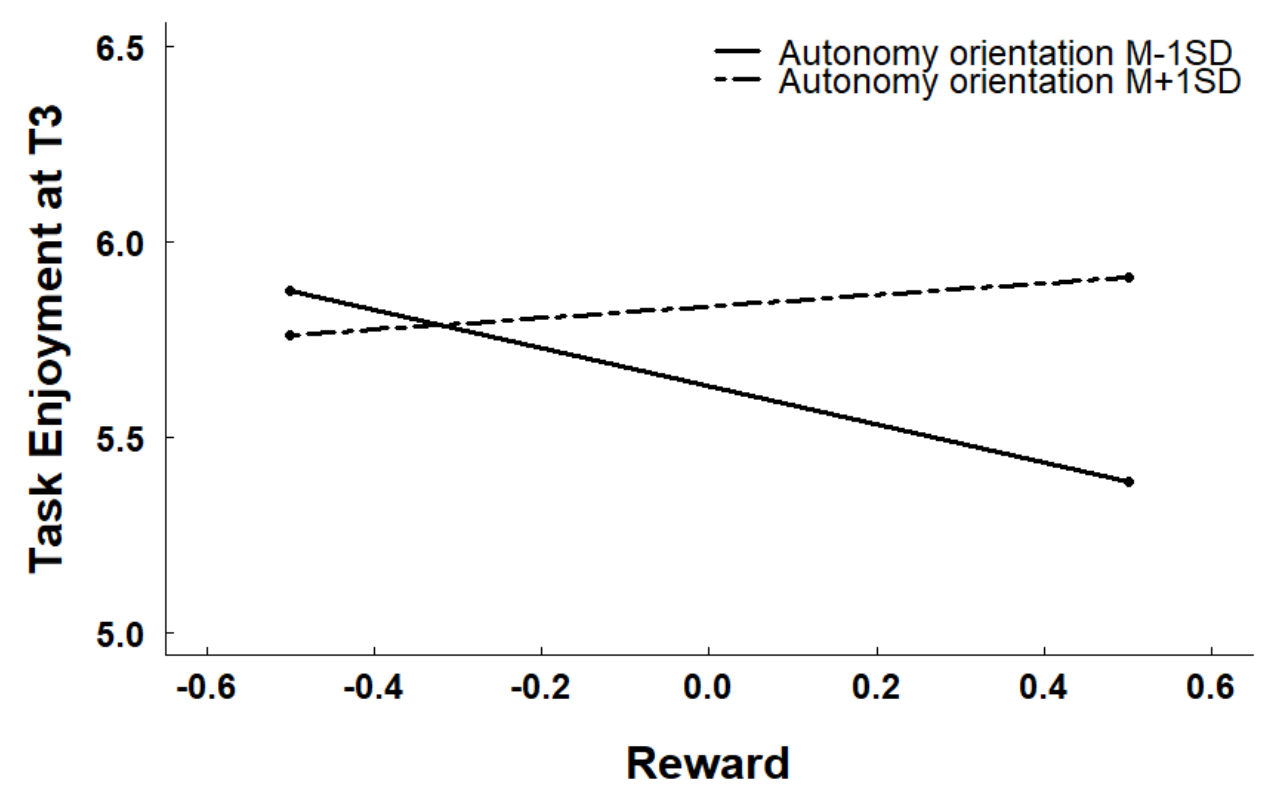
Time 3.

Figure 5. Interaction effect between reward and autonomy orientation on task enjoyment at

Note. The no reward and reward conditions were coded as 0 and 1, respectively.

Figure 6 shows the confidence band of the interaction effects of autonomy orientation and reward on task enjoyment at Time 3 . The regression of task enjoyment on reward for individuals with low autonomy orientation was significant when the centred score of autonomy orientation was lower than -.20 . 


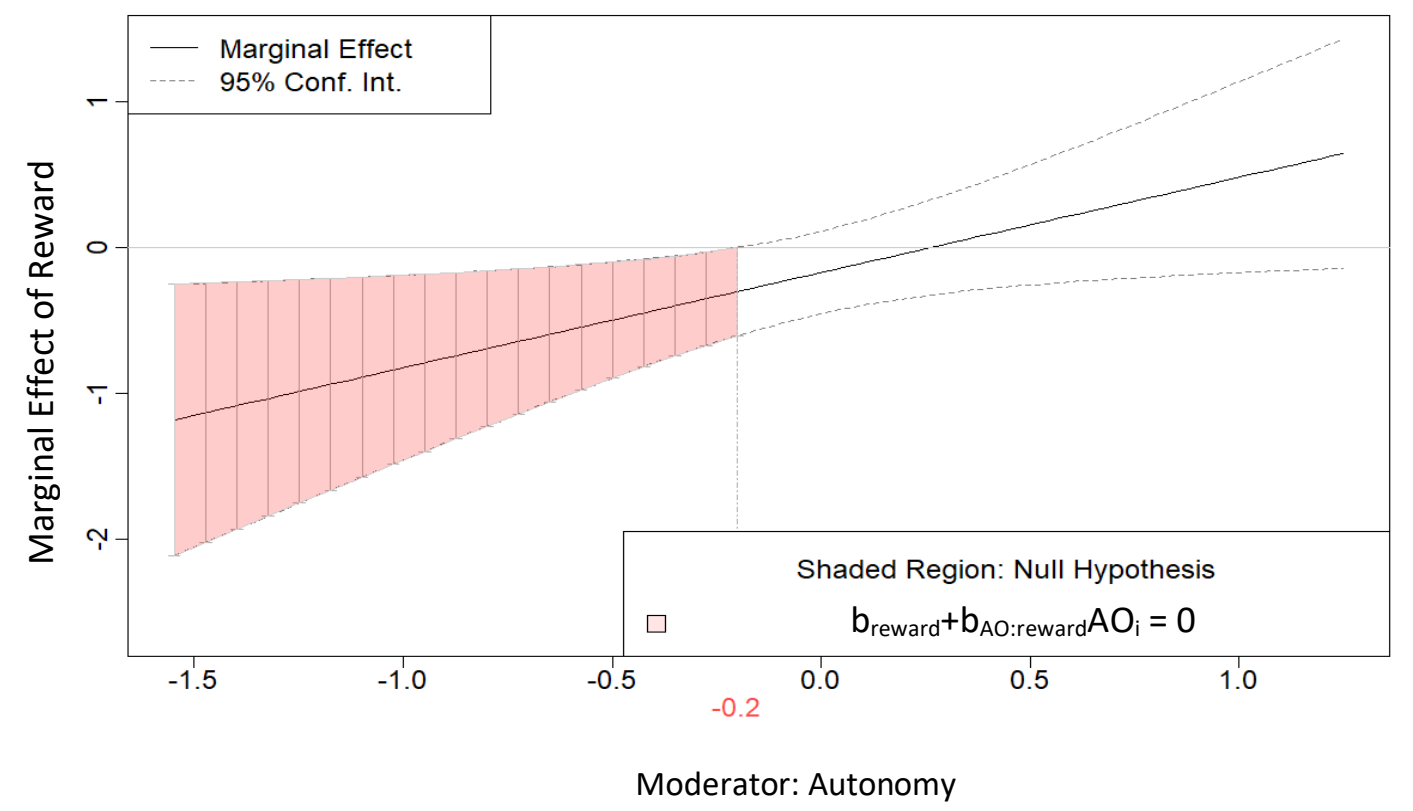

Figure 6. Confidence band of interaction effects of reward and autonomy orientation (AO) on task enjoyment at Time 3.

Note. The standard deviation of centred autonomy orientation was .49 , and the possible range of centred autonomy orientation was -1.31 to 1.02 .

\section{Discussion}

This study examined the moderating effect of causality orientations on the effect of monetary rewards and choice on perceived competence, and whether it affected intrinsic motivation. We further aimed to explore how reward and choice would affect competence and intrinsic motivation when provided simultaneously, and whether it would be moderated by causality orientation.

Our first hypothesis was partially supported as we found a significant interaction effect of choice and autonomy orientation on perceived competence, although it did not affect intrinsic motivation. Participants with high autonomy orientation had higher perceived competence when given the choice over their task, whereas participants with low autonomy orientation had lower perceived competence. These results are in line with the findings reported by Mouratidis et al. (2011) on the interaction between daily fluctuation in need satisfaction and trait-level differences in need satisfaction. That is, just as the daily need satisfaction was higher among individuals who are good at satisfying their needs, our study found that the provision of choice had a stronger effect on perceived competence for individuals who function more autonomously. Moreover, participants in the present research completed most of the puzzle tasks $(M=8.360, S D=0.990$, nine in total). Considering that people with high autonomy orientation tend to reflect their success in fulfilling their basic psychological needs (Ryan \& Deci, 2017), they might interpret having choice over a task as an opportunity to demonstrate competence, and thus perceived themselves as competent after solving the puzzle tasks. In contrast, people with low autonomy orientation may experience frustration when facing a choice, leading to a decrease in their perceived competence.

In the current study, the effect of reward on intrinsic motivation was moderated by autonomy orientation, although the effect was not mediated by perceived competence. Reward had no significant 
effect on task enjoyment of people with high autonomy orientation. In contrast, the enjoyment of participants with low autonomy orientation decreased significantly after receiving the reward, partially supporting our first hypothesis that the negative effect of reward on intrinsic motivation will not occur in people with high autonomy orientation. This result is also in line with the findings of Hagger and Chatzisarantis (2011), who stated that people with low autonomy orientation tend to focus on the controlling aspect of the reward, attributing their actions to this external environmental factor instead of to their own will, which consequently suppresses their intrinsic motivation towards the task. Although the positive correlation between time spent on puzzles and task enjoyment in each time period were all significant, we found no significant interaction effect of autonomy orientation and reward on the behavioural index of intrinsic motivation. This might be because during the free choice periods, participants were given new illustrations of puzzle configurations that required the use of all seven pieces of the soma cube to complete. We increased the difficulty to prevent participants from getting used to the puzzle and yield to boredom; however, this change in difficulty might have confounded with the effect of our manipulation of reward and the effect of autonomy orientation on the behaviour index of intrinsic motivation.

We did not find any significant interaction effect between reward and choice on competence and intrinsic motivation; autonomy orientation did not moderate interaction effects. Our study followed the methods of Deci (1971), who aimed to verify whether the external contingency of monetary reward can motivate people only as long as it exists. We adapted this method to examine whether the effect of choice on intrinsic motivation could last even after we withdraw the provision of that choice. Our results showed that the effect of choice was powerful enough to affect the participants' competence even after we stopped providing that choice. Nevertheless, the procedure of the present research still needs some modification, which will be discussed in the limitation section.

Our second hypothesis was not supported, as the results showed no significant interaction effect between reward, choice, and controlled orientation on intrinsic motivation. These non-significant results could be attributed to the relatively high autonomy orientation and low controlled orientation in most of our participants, such that the effect of controlled orientation was weak even after we controlled the effect of autonomy orientation. This made it difficult to infer how individuals with high controlled orientation would react to reward, despite our dimensional analysis of causality orientation. Controlled orientation is suggested to be associated with type-A personality (Deci \& Ryan, 1985, 2000), which is a pattern of behaviours and emotions with an excessive emphasis on competition, aggression, impatience, and hostility (Friedman \& Booth-Kewley, (1987). Controlled orientation is also highly related to public self-consciousness, and problems with gambling and alcohol use. A high controlled orientation is linked to motivation and persistence, but this type of motivation is non-optimal and predictive of poorer well-being than an autonomy orientation (Ryan \& Deci, 2017).

The interaction effects between reward, choice, and impersonal orientation on both perceived competence and intrinsic motivation were not significant. While these results are consistent with our third hypothesis, it is difficult to determine whether the third hypothesis was supported or not, due to potential type II error caused by the imbalance in causality orientations among our participants. The negative correlation between impersonal orientation and perceived competence in all three time periods were significant. According to Deci and Ryan $(1985,2000)$, people with high impersonal orientation tend to see themselves as incompetent and unable to master situations, which makes them generally difficult to motivate. Consequently, they develop a pervasive sense of incompetence that leaves them vulnerable to failure experiences, depressive symptoms, social anxiety, low self-esteem, hostility, and a procrastinatory approach to decision making. More studies on how to motivate people with high impersonal orientation are necessary. However, it might be more important to understand how to create an environment that consistently satisfies students' psychological needs such that they can develop a strong autonomy orientation instead of an impersonal orientation. 


\subsection{Limitations}

Our study provides preliminary support for the moderating effect of causality orientation on the relationship between environmental conditions and intrinsic motivation; however, some limitations should be considered. First, we did not conduct a power analysis or other sample size justification prior to participant recruitment. Future studies should use the effect sizes of the present research to calculate a sufficient sample size for achieving adequate power. Second, the distribution of causality orientations in our sample was unbalanced. Our methodology could be improved by screening participants for high and low causality orientations before randomization into conditions. Future studies could also recruit participants from different classes, schools, regions, or even populations that are not university students. Third, the paradigm used to examine the effect of choice in the present study needs to be modified. A simple design of two levels (choice vs no choice) with a single step might be the proper way to achieve our initial goal. Fourth, the artificial setting in which the study was conducted may cast doubt on its ecological validity, especially as it focused on intrinsic motivation.

\subsection{Conclusion}

Tailoring motivation according to individual differences might be difficult to execute in reallife contexts. As it is virtually impossible for one teacher to teach dozens of students in different ways in the traditional education system, or creating a collaborative environment that fits every employees' motivational needs. However, the recent dramatic development of technology use in different contexts can facilitate the development of more robust resources for everyone, for instance, by employing personalized learning systems grounded in research on learner differences to adapt to each student's needs and characteristics. Future studies could also explore training on motivation self-regulation in relation to individual contingencies, as an alternative approach to developing personalized support system.

\section{Funding}

This work was supported by JSPS KAKENHI (Grant Number 16K11978, 16H06406).

\section{Keypoints}

- The negative effect of reward on intrinsic motivation only occurred in people with low autonomy orientation.

- Providing choice enhanced perceived competence of people with high autonomy orientation but undermined it in people with low autonomy orientation.

- Impersonal orientation was negatively related to perceived competence. 


\section{References}

Aiken, L. S., West, S. G., \& Reno, R. R. (1991). Multiple regression: Testing and interpreting interactions. Sage.

Baumeister, R. F., Bratslavsky, E., Muraven, M., \& Tice, D. M. (1998). Ego-depletion: Is the active self a limited resource? Journal of Personality and Social Psychology, 74, 1252-1265. https://doi.org/10.1037/0022-3514.74.5.1252

Black, A. E., \& Deci, E. L. (2000). The effects of instructors' autonomy support and students' autonomous motivation on learning organic chemistry: A self-determination theory perspective. Science Education, $\quad 84, \quad 740-756 . \quad$ https://doi.org/10.1002/1098-237X(200011)84:6\%3C740::AIDSCE4\%3E3.0.CO;2-3.

Bong, M., \& Clark, R. E. (1999). Comparison between self-concept and self-efficacy in academic $\begin{array}{lllll}\text { motivation } & \text { research. Educational }\end{array}$ https://doi.org/10.1207/s15326985ep3403_1

Brandstätter, V., Job, V., \& Schulze, B. (2016). Motivational incongruence and well-being at the workplace: Person-job fit, job burnout, and physical symptoms. Frontiers in Psychology, 7, 1153. https://doi.org/10.3389/fpsyg.2016.01153

*Byron, K., \& Khazanchi, S. (2012). Rewards and creative performance: A meta-analytic test of theoretically derived hypotheses. Psychological Bulletin, 138, 809-830. https://doi.org/10.1037/a0027652

Cameron, J. (2001). Negative effects of reward on intrinsic motivation-A limited phenomenon: Comment on Deci, Koestner, and Ryan (2001). Review of Educational Research, 71, 29-42. https://doi.org/10.3102/00346543071001029

Cameron, J., Pierce, W. D., Banko, K. M., \& Gear, A. (2005). Achievement-based rewards and intrinsic motivation: A test of cognitive mediators. Journal of Educational Psychology, 97, 641-655. https://doi.org/10.1037/0022-0663.97.4.641.

Catania, G., \& Randall, R. (2013). The relationship between age and intrinsic and extrinsic motivation in workers in a Maltese cultural context. International Journal of Arts \& Sciences, 6, 31-45.

*Cerasoli, C. P., Nicklin, J. M., \& Ford, M. T. (2014). Intrinsic motivation and extrinsic incentives jointly predict performance: A 40-year meta-analysis. Psychological Bulletin, 140, 980. https://doi.org/10.1037/a0035661

Cohen, D. S. (1974). The effects of task choice, monetary, and verbal reward on intrinsic motivation: A closer look at Deci's cognitive evaluation theory. Unpublished doctoral dissertation, Ohio State University.

Cohen, J. (1988). Statistical power analysis for the behavioral sciences. Hillsdale, New Jersey: Lawrence Erlbaum Associates.

Covington, M. V., \& Müeller, K. J. (2001). Intrinsic versus extrinsic motivation: An approach/avoidance reformulation. Educational Psychology Review, 13, 157-176. https://doi.org/10.1023/A:1009009219144

DeCharms, Richard (1968), Personal Causation. New York: Academic Press.

Deci, E. L. (1971). Effects of externally mediated rewards on intrinsic motivation. Journal of Personality and Social Psychology, 18, 105-115. https://doi.org/10.1037/h0030644

Deci, E. L. (1980). The psychology of self-determination. DC Heath and Company.

Deci, E. L., \& Ryan, R. M. (1985). The general causality orientations scale: Self-determination in personality. Journal of Research in Personality, 19, 109-134. https://doi.org/10.1016/00926566(85)90023-6

Deci, E. L., \& Ryan, R. M. (2000). The "what" and "why" of goal pursuits: Human needs and the selfdetermination of behavior. Psychological Inquiry, 11, 227-268. https://doi.org/10.1207/S15327965PLI1104_01

Deci, E. L., Koestner, R., \& Ryan, R. M. (2001). Extrinsic rewards and intrinsic motivation in education: Reconsidered once again. Review of Educational Research, 71, 1-27. https://doi.org/10.3102/00346543071001001

Elliot, A. J., \& Hulleman, C. S. (2017). Achievement goals. In A. J. Elliot, C. S. Dweck, \& D. S. Yeager 
(Eds.), Handbook of competence and motivation: Theory and application (p. 43-60). The Guilford Press.

Gilakjani, A. P. (2012). A match or mismatch between learning styles of the learners and teaching styles of the teachers. International Journal of Modern Education and Computer Science, 4, 51-60. https://doi.org/10.5815/ijmecs.2012.11.05

Hagger, M. S., \& Chatzisarantis, N. L. D. (2011). Causality orientations moderate the undermining effect of rewards on intrinsic motivation. Journal of Experimental Social Psychology, 47, 485-489. https://doi.org/10.1016/j.jesp.2010.10.010

Hendijani, R., Bischak, D. P., Arvai, J., \& Dugar, S. (2016). Intrinsic motivation, external reward, and their effect on overall motivation and performance. Human Performance, 29, 251-274. https://doi.org/10.1080/08959285.2016.1157595

Huang, Y., Lv, W., \& Wu, J. (2016). Relationship between intrinsic motivation and undergraduate students' depression and stress: the moderating effect of interpersonal conflict. Psychological Reports, 119, 527-538. doi: 10.1177/0033294116661512

Houlfort, N., Koestner, R., Joussemet, M., Nantel-Vivier, A., \& Lekes, N. (2002). The impact of performance-contingent rewards on perceived autonomy and competence. Motivation and Emotion, 26, 279-295.

How, Y. M., Whipp, P., Dimmock, J., \& Jackson, B. (2013). The effects of choice on autonomous motivation, perceived autonomy support, and physical activity levels in high school physical education. Journal of Teaching in Physical Education, 32, 131-148. DOI: 10.1123/jtpe.32.2.131

Jellison, J. M., \& Harvey, J. H. (1973). Determinants of perceived choice and the relationship between perceived choice and perceived competence. Journal of Personality and Social Psychology, 28, 376382. https://doi.org/10.1037/h0035110

Johnson, P. E. (2019). Using rockchalk for Regression Analysis. https://mirrors.nics.utk.edu/cran/web/packages/rockchalk/vignettes/rockchalk.pdf

Jovanovic, D., \& Matejevic, M. (2014). Relationship between rewards and intrinsic motivation for learning-Researches Review. Procedia-Social and Behavioral Sciences, 149, 456-460. https://doi.org/10.1016/j.sbspro.2014.08.287

Kakinuma, K., Nakai, M., Hada, Y., Kizawa, M., \& Tanaka, A. (2020). Praise affects the "Praiser": Effects of ability-focused vs. effort-focused praise on motivation. The Journal of Experimental Education, 1-22. https://doi.org/10.1080/00220973.2020.1799313

Khalaila, R. (2015). The relationship between academic self-concept, intrinsic motivation, test anxiety, and academic achievement among nursing students: Mediating and moderating effects. Nurse Education Today, 35, 432-438. https://doi.org/10.1016/j.nedt.2014.11.001

Kozlowski, S. W. (Ed.). (2012). The Oxford handbook of organizational psychology (Vol. 1). Oxford University Press.

Lepper, M. R., Corpus, J. H., \& Iyengar, S. S. (2005). Intrinsic and extrinsic motivational orientations in the classroom: Age differences and academic correlates. Journal of Educational Psychology, 97, 184-196. https://doi.org/10.1037/0022-0663.97.2.184

Li, Y., Wei, F., Ren, S., \& Di, Y. (2015). Locus of control, psychological empowerment and intrinsic motivation relation to performance. Journal of Managerial Psychology, 30, 422-438. https://doi.org/10.1108/JMP-10-2012-0318

Iyengar, S. S., \& Lepper, M. R. (1999). Rethinking the value of choice: a cultural perspective on intrinsic motivation. Journal of Personality and Social Psychology, 76, 349-366. https://doi.org/10.1037/0022-3514.76.3.349

Iyengar, S. S., \& Lepper, M. R. (2000). When choice is demotivating: Can one desire too much of a good thing? Journal of Personality and Social Psychology, 79, 995-1006. https://doi.org/10.1037/00223514.79.6.995

$\mathrm{Ng}$, B. (2018). The neuroscience of growth mindset and intrinsic motivation. Brain Sciences, 8, 20-30.

Marinak, B. A. (2004). The effects of reward proximity and choice of reward on the reading motivation of third-grade students. Unpublished doctoral dissertation, University of Maryland, College Park.

McAdams, D. P., \& Pals, J. L. (2006). A new Big Five: fundamental principles for an integrative science of personality. American Psychologist, 61, 204-217. https://doi.org/10.1037/0003-066X.61.3.204 
Mouratidis, A., Vansteenkiste, M., Sideridis, G., \& Lens, W. (2011). Vitality and interest-enjoyment as a function of class-to-class variation in need-supportive teaching and pupils' autonomous motivation. Journal of Educational Psychology, 103, 353-366. https://doi.org/10.1037/a0022773

Mistree, F., Panchal, J. H., Schaefer, D., Allen, J. K., Haroon, S., \& Siddique, Z. (2014). Personalized engineering education for the twenty-first century. In M. Gosper, \& D. Ifenthaler (Eds,), Curriculum Models for the 21st Century (pp. 91-111). Springer.

Murayama, K., Matsumoto, M., Izuma, K., \& Matsumoto, K. (2010). Neural basis of the undermining effect of monetary reward on intrinsic motivation. Proceedings of the National Academy of Sciences, 107(49), 20911-20916. https://doi.org/10.1073/pnas.1013305107

Omansky, R., Eatough, E. M., \& Fila, M. J. (2016). Illegitimate tasks as an impediment to job satisfaction and intrinsic motivation: Moderated mediation effects of gender and effort-reward imbalance. Frontiers in Psychology, 7, 1818. https://doi.org/10.3389/fpsyg.2016.01818

Patall, E. A. (2012). The motivational complexity of choosing: a review of theory and research. In R. M. Ryan (Ed.), The Oxford handbook of human motivation. USA: Oxford University Press.

*Patall, E. A., Cooper, H., \& Robinson, J. C. (2008). The effects of choice on intrinsic motivation and related outcomes: A meta-analysis of research findings. Psychological Bulletin, 134, 270-300. https://doi.org/10.1037/0033-2909.134.2.270

Putra, E. D., Cho, S., \& Liu, J. (2017). Extrinsic and intrinsic motivation on work engagement in the hospitality industry: Test of motivation crowding theory. Tourism and Hospitality Research, 17, 228-241. https://doi.org/10.1177/1467358415613393

Patall, E. A., Cooper, H., \& Wynn, S. R. (2010). The effectiveness and relative importance of choice in the classroom. Journal of Educational Psychology, 102, 896-915. https://doi.org/10.1037/a0019545

*Rawsthorne, L. J., \& Elliot, A. J. (1999). Achievement goals and intrinsic motivation: A meta-analytic review. Personality and Social Psychology Review, 3, 326-344. https://doi.org/10.1207/s15327957pspr0304_3

Ryan, R. M. (1982). Control and information in the intrapersonal sphere: An extension of cognitive evaluation theory. Journal of Personality and Social Psychology, 43, 450-461. https://doi.org/10.1037/0022-3514.43.3.450

Ryan, R. M., \& Deci, E. L. (2006). Self - regulation and the problem of human autonomy: Does psychology need choice, self - determination, and will? Journal of Personality, 74, 1557-1586. https://doi.org/10.1111/j.1467-6494.2006.00420.x

Ryan, R. M., \& Deci, E. L. (2017). Self-determination theory: Basic psychological needs in motivation, development, and wellness. Guilford Press.

Skaalvik, S., \& Skaalvik, E. M. (2004). Gender differences in math and verbal self-concept, performance expectations, and motivation. Sex Roles, 50, 241-252. https://doi.org/10.1023/B:SERS.0000015555.40976.e6

Skinner, E. A., \& Belmont, M. J. (1993). Motivation in the classroom: Reciprocal effects of teacher behavior and student engagement across the school year. Journal of Educational Psychology, 85, 571-581. https://doi.org/10.1037/0022-0663.85.4.571

Tanaka, H., \& Sakurai, S. (1995). Construction of the Japanese Version of the General Causality Orientations Scale. Nara University of Education Academic Repository, 31, 177-184.

WANG, J. H. Y., \& Guthrie, J. T. (2004). Modeling the effects of intrinsic motivation, extrinsic motivation, amount of reading, and past reading achievement on text comprehension between US and Chinese students. Reading Research Quarterly, 39, 162-186. DOI: 10.1598/RRQ.39.2.2

Warneken, F., \& Tomasello, M. (2008). Extrinsic rewards undermine altruistic tendencies in 20-montholds. Developmental Psychology, 44, 1785. https://doi.org/10.1037/a0013860

Woolley, K., \& Fishbach, A. (2018). It's about time: Earlier rewards increase intrinsic motivation. Journal of Personality and Social Psychology, 114, 877-890. https://doi.org/10.1037/pspa0000116 


\section{Appendix}

We conducted a series of multiple regressions using causality orientation, reward, and task choice as predictor variables; and time spent on puzzles, task enjoyment, and perceived competence of Time 2 as outcome variables, while controlling the objective variables of Time 1 . We also examined the interaction effect between causality orientation and reward, and causality orientation and task choice on outcome variables. All results reported below are from the final, trimmed models; participants' gender, age, and the number of solved puzzles at Time 2 were controlled in each model.

Table A-1 shows the results of multiple regression concerning perceived competence at Time 2 . No significant main effect and interaction effects were found. Table A-2 shows the results of multiple regression concerning time spent on puzzles at Time 2 . The main effect of task choice was significant $(\beta=-.194, p=.016)$. This result indicated that compared to those participants who were not able to choose the order of solving puzzles, the participants who were able to choose the order of solving puzzles during Time 2 spent significantly less time on the puzzles during the free-choice period that followed. The main effect of causality orientation and reward, and interaction effects between causality orientation and reward, and causality orientation and task choice were not significant. Table A-3 shows the results of multiple regression concerning task enjoyment at Time 2. No significant main effect and interaction effects were found. 
Table A-1

Multiple regression results concerning Perceived Competence at Time 2.

\begin{tabular}{|c|c|c|c|c|c|c|c|c|c|c|}
\hline & \multicolumn{10}{|c|}{ Perceived Competence [T2] } \\
\hline & \multicolumn{6}{|c|}{ Step 1} & \multicolumn{4}{|c|}{ Step 2} \\
\hline & \multirow{2}{*}{\multicolumn{4}{|c|}{ E }} & \multirow{2}{*}{\multicolumn{2}{|c|}{ CI ${ }^{95 \%}$}} & \multirow{2}{*}{\multicolumn{3}{|c|}{ E }} & \multirow{2}{*}{$95 \% \mathrm{CI}$} \\
\hline & & & & & & & & & & \\
\hline Autonomy Orientation & .127 & 235 & .045 & 590 & $\begin{array}{r}{ }^{[-} \\
.512, .723]\end{array}$ & .154 & 241 & .055 & 526 & {$[-.635, .328]$} \\
\hline Controlled Orientation & 464 & 258 & .161 & 076 & $\begin{array}{r}{[-} \\
.050, .978]\end{array}$ & $\begin{array}{r}.49 \\
7\end{array}$ & 264 & .173 & $\begin{array}{r}.06 \\
4\end{array}$ & {$[-.030,1.023]$} \\
\hline Impersonal Orientation & .109 & 215 & .040 & 613 & $.539, .320]$ & .127 & 219 & .046 & 566 & {$[-.564, .311]$} \\
\hline Competence [T1] & 573 & 075 & .652 & 000 & $\begin{array}{r}{[} \\
.424, .723] \\
\end{array}$ & 567 & 076 & .645 & 000 & {$[.416, .719]$} \\
\hline Reward & & & & & & .152 & 218 & .056 & 486 & {$[-.586, .282]$} \\
\hline Task Choice & & & & & & 139 & 204 & .051 & 497 & {$[-.268, .547]$} \\
\hline$R^{2}$ & & .60 & & & & & .6 & & & \\
\hline$\Delta R^{2}$ & & & & & & & .0 & & & \\
\hline
\end{tabular}

Note. Insignificant interaction effects were removed from the final models. Gender, age, and number of solved puzzles at Time 2 were included as control variables, but results are omitted for brevity. $\Delta R^{2}$ shows the change in $R^{2}$ when adding interaction effects into the model. 
Table A-2

Multiple regression results concerning Time Spent on Puzzles at Time 2.

\begin{tabular}{|c|c|c|c|c|c|c|c|c|c|c|}
\hline & \multicolumn{10}{|c|}{ Time Spent on Puzzles [T2] } \\
\hline & \multicolumn{5}{|c|}{ Step 1} & \multicolumn{5}{|c|}{ Step 2} \\
\hline & $\mathrm{B}$ & $E$ & & & $95 \% \mathrm{CI}$ of $\mathrm{B}$ & B & $E$ & $S$ & & $95 \% \mathrm{CI}$ of $\mathrm{B}$ \\
\hline \multicolumn{11}{|l|}{ Causality Orientations } \\
\hline Autonomy Orientation & $11.360^{-}$ & $5.948^{2}$ & .041 & 663 & $\begin{array}{l}\quad[-63.086, \\
40.366]\end{array}$ & $6.178^{-}$ & 5.074 & $\begin{array}{l}2.022 \\
.022\end{array}$ & 806 & $\begin{array}{l}\quad[-56.187, \\
43.831]\end{array}$ \\
\hline Controlled Orientation & $8.060^{-}$ & $6.540^{2}$ & .028 & 762 & {$[-60.967,44.847]$} & -12.986 & 5.705 & $\begin{array}{l}2 . \\
.045\end{array}$ & 615 & {$[-64.254,38.282]$} \\
\hline Impersonal Orientation & $\begin{array}{r}1 \\
5.791\end{array}$ & $3.696^{2}$ & .057 & 507 & $\begin{array}{c}{[-31.447} \\
63.028]\end{array}$ & $\begin{array}{r}1 \\
6.672\end{array}$ & 2.705 & 2.061 & 465 & $\begin{array}{c}{[-28.611} \\
61.954]\end{array}$ \\
\hline Time Spent on Puzzles [T1] & 898 & .109 & .738 & 000 & $\begin{array}{l}{[.681,} \\
1.114]\end{array}$ & $\begin{array}{r}.9 \\
17 \\
\end{array}$ & .107 & .754 & 000 & $\begin{array}{l}{[.704,} \\
1.130]\end{array}$ \\
\hline Reward & & & & & & $\begin{array}{r}3 \\
4.274\end{array}$ & 3.210 & $\begin{array}{l}2.126 \\
\end{array}$ & 144 & $\begin{array}{l}{[-12.016,} \\
80.564]\end{array}$ \\
\hline Task Choice & & & & & & 52.562 & 1.249 & $\begin{array}{l}2 . \\
.194\end{array}$ & 016 & $\begin{array}{l}{[-94.942,} \\
10.183]\end{array}$ \\
\hline $\begin{array}{l}R^{2} \\
\Delta R^{2}\end{array}$ & & .526 & & & & & $\begin{array}{l}.587 \\
.054 \\
\end{array}$ & & & \\
\hline
\end{tabular}

Note. Insignificant interaction effects were removed from the final models. Gender, age, and number of solved puzzles at Time 2 were included as control variables, but the results are omitted for brevity. $\Delta \mathrm{R} 2$ shows the change in R2 when adding interaction effects into the model 
Table A-3

Multiple regression results concerning Task Enjoyment at Time 2.

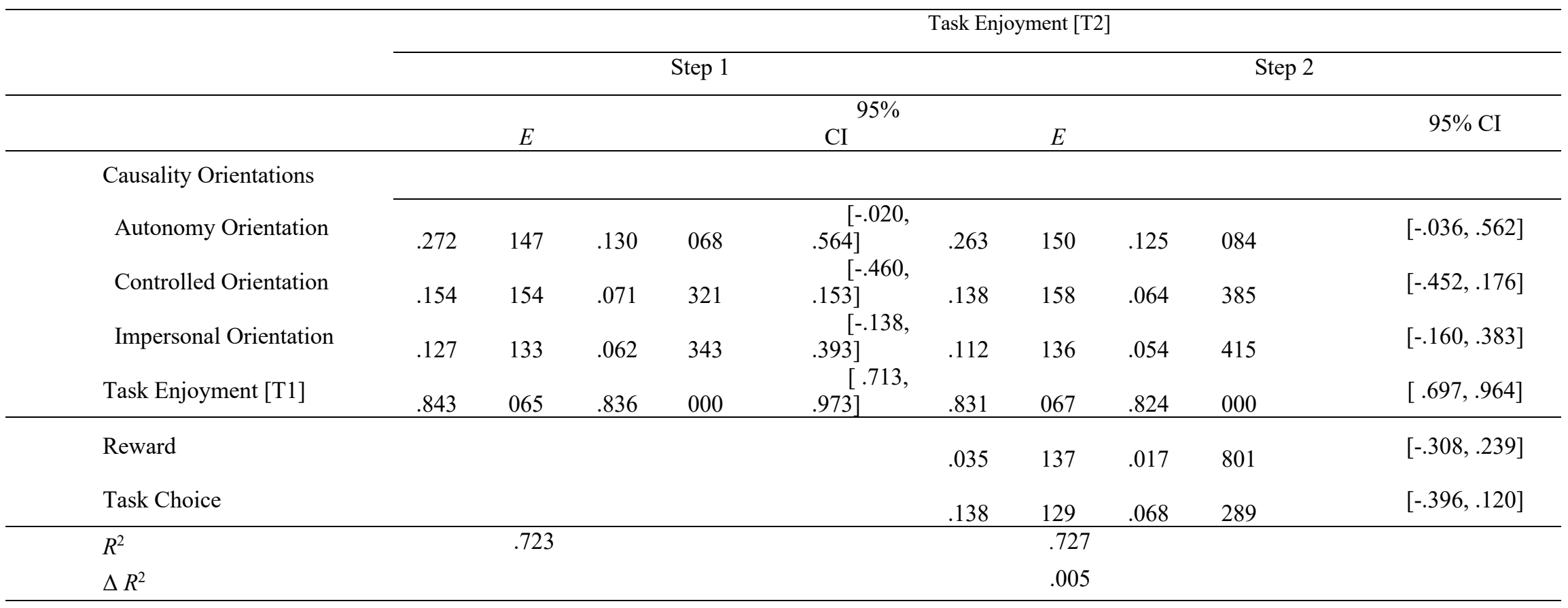

Note. Insignificant interaction effects were removed from the final models. Gender, age, and number of solved puzzles at Time 2 were included as control variables, but the results are omitted for brevity. $\Delta R^{2}$ shows the change in $R^{2}$ when adding interaction effects into the model. 